\title{
Application of Geographic Information System (GIS) in Hydropower Resource Assessment: A Case Study in Misamis Occidental, Philippines
}

\author{
Rovick P. Tarife, Anacita P. Tahud, Ellen Jane G. Gulben, Haroun Al Raschid Christopher P. \\ Macalisang, and Ma. Teresa T. Ignacio
}

\begin{abstract}
This study focuses on the application of Geographical Information Systems (GIS) tools in identifying and classifying the theoretical hydropower potential sites in Misamis Occidental, a province located in the region of Northern Mindanao in the Philippines. GIS based hydrological modeling is performed on raster cells using topographical and meteorological datasets. Input datasets include Digital Elevation Model (DEM), landuse-landcover, soil map, watershed boundary, weather data (precipitation, humidity and temperature). The study has shown that $62 \%$ of the potential sites are classified as micro hydropower $(5 \mathrm{~kW}-100 \mathrm{~kW}$ potential capacity) and $38 \%$ are classified as pico (less than $5 \mathrm{~kW}$ ). The results of this study will help policy makers, public authorities, and investors in the energy sector to optimize the available resources in selecting the suitable sites for small hydropower plants with high power potential.
\end{abstract}

Index Terms-GIS, hydropower, renewable energy, resource assessment.

\section{INTRODUCTION}

Increasing demands for energy and concerns over devastating effects of climate change have spurred interest in energy from renewable sources. Many forward-thinking countries are taking a closer look at their renewable energy resources to determine which, if any, are suitable for development [1]. There are various renewable energy options including wind, solar, biomass and hydroelectric energy sources. Hydropower is apparently the most common form of renewable energy option [2]. In order to tap the potential of these renewable energy sources, there is a need to assess the availability of the resources spatially [3].

In the Philippines, hydropower is the dominant renewable energy source. Hydropower contributes $13.31 \%$ of the country's energy needs [4]. By the year 2030, the country's energy sector targets to triple the country's renewable energy capacity and in particular, to increase hydropower installed

Manuscript received November 4, 2016; revised February 12, 2017. This work was fully supported by the Department of Science and Technology (DOST) under its Phil-LiDAR 2 Program.

R. P. Tarife, A. P. Tahud, and E. J. G. Gulben are with the Phil-LiDAR 2 College of Engineering, Mindanao State University - Iligan Institute of Technology (MSU-IIT), Iligan City, Philippines (e-mail: rovicktarife@gmail.com, anapalmatahud@gmail.com, luxlucis.ejg@gmail.com).

H. A. R. C. P. Macalisang is with the Phil-LiDAR 2 and the Department of Computer Science, School of Computer Studies, MSU-IIT, Iligan City, Philippines (e-mail: haroun.macalisang@g.msuiit.edu.ph).

M. T. T. Ignacio is with the Phil-LiDAR 2 and the Department of Metallurgical Engineering, College of Engineering, MSU-IIT, Iligan City, Philippines (e-mail: materesa.ignacio@g.msuiit.edu.ph). capacity by an additional of approximately 5,394 MW [5]. With its estimated hydropower potential of $15,615 \mathrm{MW}$, approximately $77 \%$ still remains unharnessed.

Identifying a suitable site for such a small-scale hydropower development requires a detailed ground survey by a specialist team. However, it is not practical to survey all, or even most, of a country or region because of cost, manpower and security constraints. Therefore their search must be carefully targeted to the areas which are most likely to yield viable and useful sites [6].

This study focuses on the application of Geographical Information Systems (GIS) tools in identifying and classifying the theoretical hydropower potential sites in Misamis Occidental, a province located in the region of Northern Mindanao in the Philippines.

\section{A. Run-of-River Hydropower System}

There are various sizes of hydropower plants ranging from very large with big dams to small run-of-river projects. The small hydropower projects need low initial investments, smaller area, shorter planning and construction time, locally trained manpower, indigenous material, and lower power generation cost as compared to larger power projects [7].

In recent years, run-of-river hydropower projects have emerged as a viable, low-impact alternative to existing large-scale projects. Run-of-the-river facilities use conventional hydropower technology to produce electricity by diverting river via a pipeline called a penstock through turbines that spin generators - before returning water back to the river downstream [8]. Fig. 1 shows the typical set up of a run-of-river facility [9].

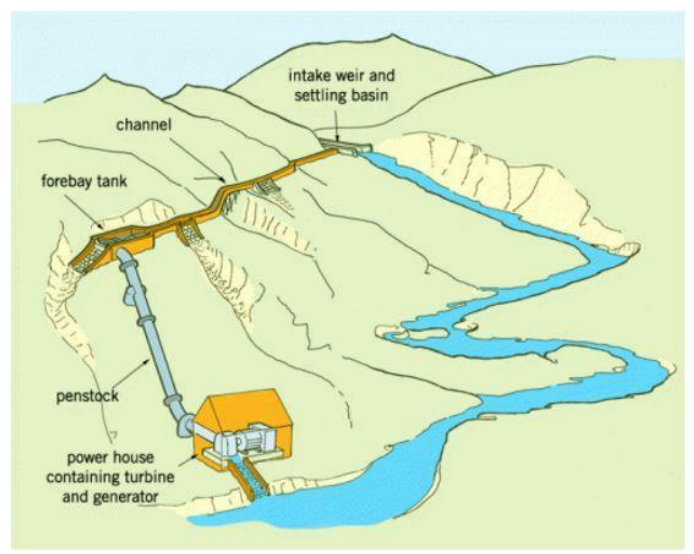

Fig. 1. Typical scheme of a run-of-river facility.

Run-of-river projects are classified into two types; low head and high head. Low head projects are usually suitable 
for large rivers that have gentle gradients, whereas, the high head types are more appropriate for small rivers having steep gradients.

\section{B. Geographic Information Systems (GIS)}

GIS are useful for specifying different type of the models. GIS can also be used to analyze data for the creation of a model. Building a model requires data exploration and analysis, algorithm specification, and accuracy assessment. GIS can be useful in all three steps

With the growing advancement of data processing in computational-GIS and accessibility of satellite imagery information, the development of a number of methodologies for the extraction of terrain characteristics from DEM (Digital Elevation Models), as drainage network position, length and slope was made possible. The application of GIS-based tools and remote sensing data on hydropower survey studies have found room in a sector that has been very orthodox in the assessment tools and source of information. Those technologies have been employed in different countries in order to locate and select hydropower opportunities of different types [10].

\section{Methodology}

\section{A. The Study Area}

Misamis Occidental is located near the narrow strip of land linking Northwestern Mindanao (Fig. 2), to the North-central part of the island. Covering a total area of 2,055.22 $\mathrm{km}^{2}$ (793.52 sq $\mathrm{mi}$ ), the province is bounded on the northeast by the Mindanao Sea, east by the Iligan Bay, southeast by the Panguil Bay, and the west by the Zamboanga del Norte and Sur. Except along the coastal area, hilly and rolling land characterized the provincial terrain. Towards the western border, the terrain is particularly rugged [11].

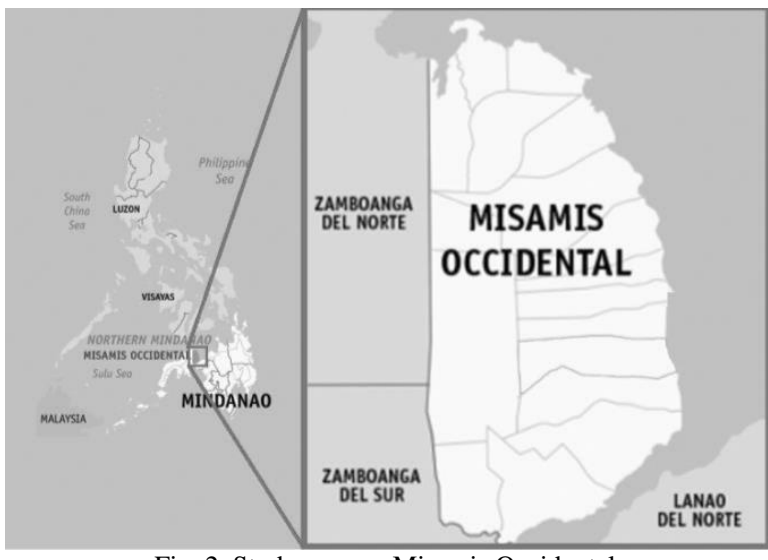

Fig. 2. Study area - Misamis Occidental.

\section{B. Discharge Analysis}

Hydrological model was built using Soil and Water Assessment Tool (SWAT) to estimate the discharge along the river lengths. The use of SWAT requires some specific data to build the hydrologic model. In this study, the input data that were used are Digital Elevation Model (DEM), stream network, land use map, soil map and weather data (precipitation, temperature, solar radiation, wind velocity, relative humidity). Before setting up SWAT model, these data were pre-processed.
ArcSWAT, an ArcGIS® extension and graphical user input interface for SWAT, was used to build a hydrological model. A surface model, which is a 10-m Synthetic Aperture Radar (SAR)-derived DEM (Fig. 3) was hydrologicallyreconditioned and used for watershed delineation and stream networks generation.

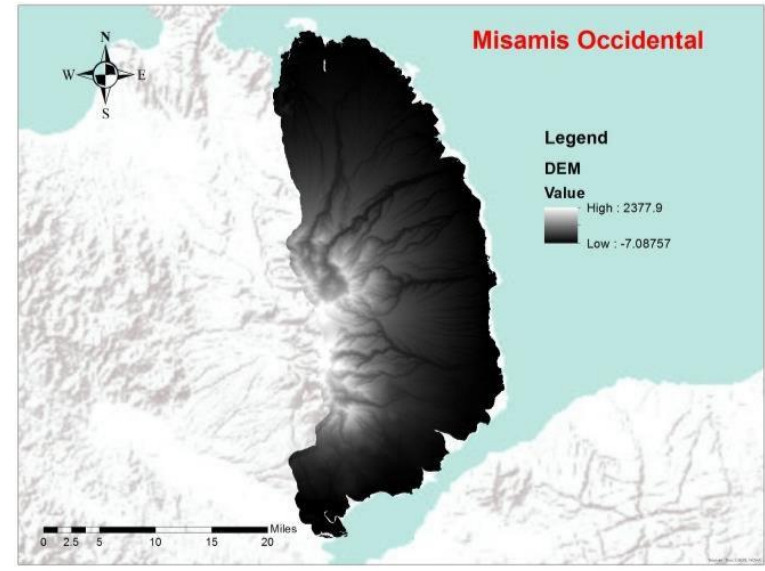

Fig. 3. SAR-derived DEM of Misamis Occidental.

\section{Optimized Head Determination Algorithm}

Head is a vertical distance between two point (intake and turbine). It can also be defined as the pressure created by elevation difference between intake and turbine.

For the initial algorithm for head determination, an algorithm developed by [12] was used. This algorithm is designed to connect river cells to see if certain criterion is fulfilled. It reads the input raster data which has the river cells where the cell values illustrate absolute elevation. Then it extracts all cells containing a value other than zero and saves them into an array of river cells. These values are ranked by height and stored in another array. This array consists of three columns containing the coordinates of the river cell, as well as its height values. To find the difference in elevation according to the criteria, the algorithm searches for the highest elevation from the river array, locates ten in a row connected cells and calculates their accumulated height difference, which corresponds to the value of the head - a necessary variable in the power computation.

The initial implementation of this algorithm was accomplished using Python programming language by University of the Philippines - Diliman Phil-LiDAR 2 Renewable Energy Resources Mapping (REMap) Using LiDAR by utilizing GDAL, OGR and OSR libraries. There are two primary inputs namely the raster dataset and the user input.

In order to improve processing time, the algorithm was optimized by MSU-IIT Phil-LiDAR 2 REMap team by utilizing parallel processing to specific portions of the program where it is applicable. The algorithm detects the computer's number of cores and allows the user to choose how many of these will be used during processing so that other applications and programs may still be used while running the head algorithm. Furthermore, to resolve other problems, the optimized program includes automatic saving function in between processes. This feature enables the user to go back to the last state of the program and continue processing which is very important during events of power 
failure. It also provides an option to abort the program at any stage which enables the user to halt the program (while saving the processing state) and continue to process the remaining portions at any time and in any other machine, without having to start from the beginning.

In this study, the criteria used were minimum head value of $20 \mathrm{~m}$ and horizontal penstock length of $100 \mathrm{~m}$.

\section{Power Computation and Classification}

ArcGIS $®$ was used in calculating the theoretical power and in storing information for each location, including head, flow and in-stream power. The estimated amount of power available from each site was determined using the formula:

$$
P=\eta_{t} \eta_{g} \rho g Q H
$$

where:

$$
\begin{aligned}
& P=\text { Hydropower potential }(\mathrm{kW}) \\
& \eta_{t}=\text { Turbine efficiency } \\
& \eta_{g}=\text { Generator efficiency } \\
& \rho=\text { Density of water }\left(1,000 \mathrm{~kg} / \mathrm{m}^{3}\right) \\
& g=\text { Acceleration due to gravity }\left(9.81 \mathrm{~m} / \mathrm{s}^{2}\right) \\
& Q=\text { Discharge or volume flow rate of water }\left(\mathrm{m}^{3} / \mathrm{s}\right) \\
& H=\text { Elevation difference between the water intake and the }
\end{aligned}
$$
powerhouse (m)

The identified potential sites were classified according to their generating capacity. Table I shows the different types of hydropower according to their generating capacity.

TABLE I: CLASSIFICATION OF HYDROPOWER ACCORDING TO GENERATING CAPACITY

\begin{tabular}{ll}
\hline \hline Hydropower Class & Generating Capacity \\
\hline Large & $>100 \mathrm{MW}$ \\
Medium & $25-100 \mathrm{MW}$ \\
Small & $1-25 \mathrm{MW}$ \\
Mini & $100 \mathrm{~kW}-1 \mathrm{MW}$ \\
Micro & $5-100 \mathrm{~kW}$ \\
Pico & $<5 \mathrm{~kW}$ \\
\hline \hline
\end{tabular}

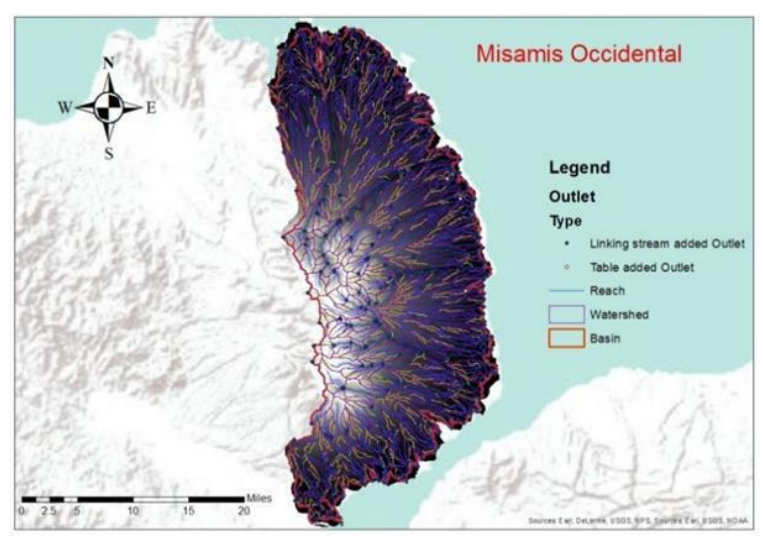

Fig. 4. Delineated watersheds and stream networks.

\section{RESUlTS AND DisCUSSION}

\section{A. Delineated Watersheds and Stream Networks}

The watersheds in the study area were delineated using the $10-\mathrm{m}$ resolution SAR-derived DEM as the main input data. Fig. 4 shows the delineated watersheds, stream networks, and basin boundary.

The basin boundary has a total area of approximately 146,507 ha $\left(1,465 \mathrm{~km}^{2}\right)$ and a perimeter of approximately
$407.49 \mathrm{~km}$. There are four main river channels in the area and a total of 576 stream reaches.

\section{B. Hydropower Potential}

The optimized head determination algorithm identified 7,592 initial sites with minimum and maximum head values of $20 \mathrm{~m}$ and $93.16 \mathrm{~m}$, respectively (Fig. 5). However, about $85 \%$ of these sites have zero discharge value and were thus excluded from identified potential hydropower sites.

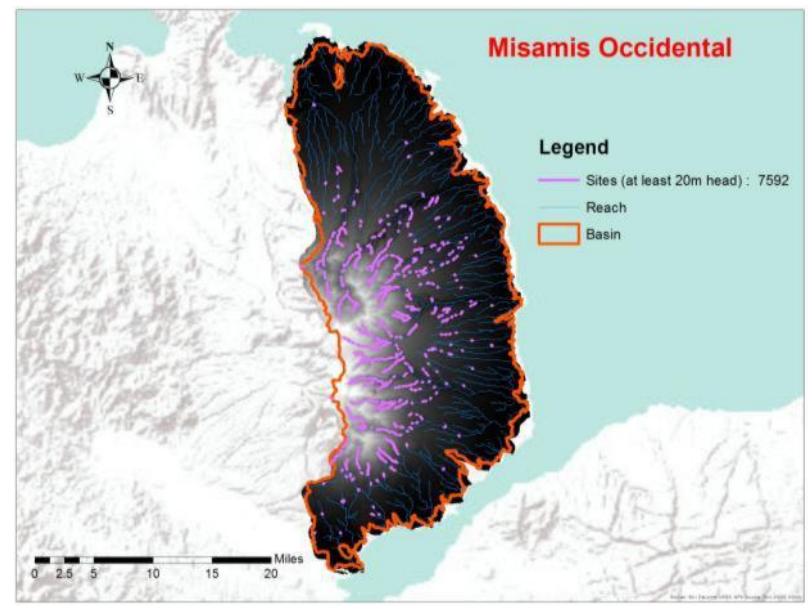

Fig. 5. Sites in Misamis Occidental with at least 20m head.

Computation of estimated power available in each site shows that there are 1,103 potential sites in Misamis Occidental (Fig. 6). The theoretical maximum and minimum potentials are $73.3 \mathrm{~kW}$ and $0.6 \mathrm{~kW}$, respectively.

Site determination was done per raster cell with step size of $10 \mathrm{~m}$ (equivalent to DEM resolution) which resulted to some adjacent and redundant potential sites. The results generally define zones of interest for future hydropower development.

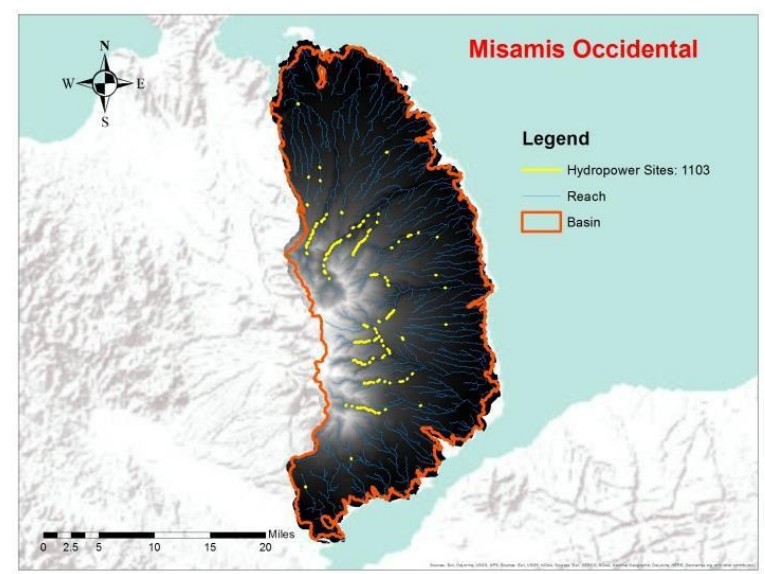

Fig. 6. Spatial distribution of potential sites for run-of-river projects.

\section{Reclassified Potential Hydropower Sites}

The identified potential hydropower sites were reclassified according to their potential generating capacity whether large (>10MW), mini (100kW to $10 \mathrm{MW})$, micro (5 to $100 \mathrm{~kW}$ ) or pico-hydro ( 1 to $5 \mathrm{~kW}$ ) system. Fig. 7 shows the reclassified sites that were categorized according to their potential generating capacity.

Results show that micro-hydropower type is dominant in Misamis Occidental with 680 identified sites or $62 \%$ of the total identified sites (Fig. 8). It also has the highest value in terms of potential (Fig. 9). 


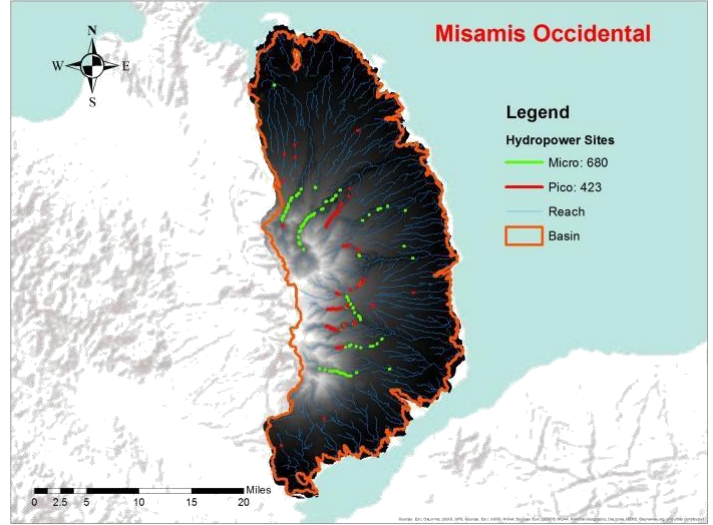

Fig. 7. Reclassified potential sites.

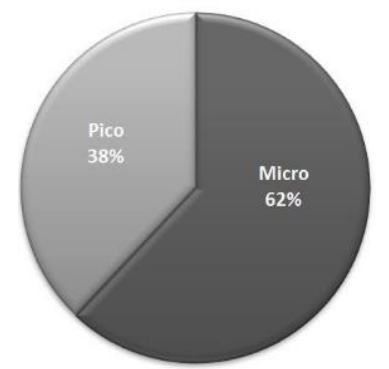

Fig. 8. Percentage of identified sites based on different hydropower classes.

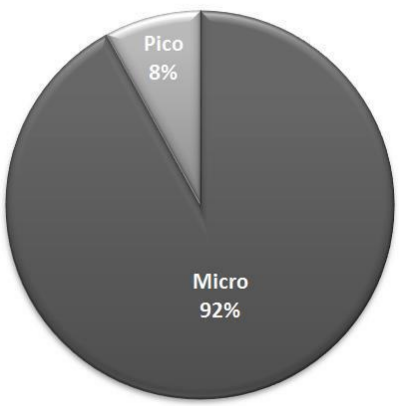

Fig. 9. Percentage of potential in $\mathrm{kW}$ for different hydropower classes.

\section{CONCLUSION}

In this study, various GIS-based spatial tools were utilized in identifying and classifying the potential hydropower sites in Misamis Occidental. The high resolution DEM that was used appropriately modeled the watersheds and stream networks. The theoretical run-of-river hydropower potential was estimated by developing the hydrological model for the province.

The work done in this study could be used to facilitate hydropower development in the province and augment the regulatory process. Furthermore, the information derived from this study is helpful to policy makers and concerned agencies in hydro energy resource management, planning and development. This could also provide a current and reliable pre-feasibility study background for possible investors and most importantly, will benefit power consumers especially those in remote areas where electricity remains unknown to them up to the present.

\section{ACKNOWLEDGMENT}

This work is under the Phil-LiDAR 2 Program: Detailed Resource Mapping in the Philippines of Mindanao State University-Iligan Institute of Technology with the supervision of Training Center for Applied Geodesy and Photogrammetry of University of The Philippines Diliman (UP-TCAGP). All authors thank Department of Science and Technology (DOST) of the Philippine government for funding this research.

\section{REFERENCES}

[1] T. Bailey and R. Bass, "Hydroelectric feasibility study: An assessment of the feasibility of generating electric power using urban stormwater in Oregon city," OIT-REE-001, June 2009.

[2] International Energy Agency (IEA), Classification of Hydropower Projects, Hydropower and the Environment: Present Context and Guidelines for Future Action Subtask, vol. II, 2000.

[3] S. Kulkarni and R. Banerjee, "Renewable energy mapping in Maharashtra, India using GIS," presented at the World Renewable Energy Congress, Sweden, May 8-13, 2011.

[4] Department of Energy. (2013). 2013 Philippine power statistics. [Online]. Available: www.doe.gov.ph/electric-power-statistics/philippines-power-statistic

[5] Department of Energy. (2013). Philippine energy plan 2012-2030. [Online]. Available: http://www2.doe.gov.ph/Presentations/PEP\%202012-2030/html/2.ht $\mathrm{m}$

[6] S. Dudhani, A. K. Sinha, and S. S. Inamdar, "Assessment of small hydropower potential using remote sensing data for sustainable development in India," Energy Policy, vol. 1, no. 34, pp. 3195-205, 2006.

[7] A. Williams. (January 2012). O run-of-the-river hydropower goes with the flow. [Online]. Available: http://www.renewableenergyworld.com/articles/print/rewna/volume-4 /issue-1/hydropower/run-of-the-river-hydropower-goes-with-the-flow html

[8] With the Flow. [Online]. Available: http://www.renewableenergyworld.com/articles/print/rewna/volume-4 /issue-1/hydropower/run-of-the-river-hydropower-goes-with-the-flow. html

[9] Practical Action. (2016). Micro-hydro power. [Online]. Available: http://practicalaction.org/simple-ideas-micro-hydro

[10] D. G. Larentis, W. Collischonn, F. Olivera, and C. E. M. Tucci, "GIS-based procedures for hydropower potential spotting," Elsevier: Energy, vol. 35, issue 10, pp. 4237-4243, October 2010.

[11] PSA. (January 2016): Province: Misamis occidental. Philippines. National Statistical Coordination Board. [Online]. Available: http://nap.psa.gov.ph/activestats/psgc/province. asp?provcode $=104200$ 000\&regName=REGION\%20X\%20(Northern\%20Mindanao)

[12] D. Bergstrom and C. Malmros, "Finding potential sites for small-scale hydro power in Uganda: A step to assist the rural electrification by the use of GIS," Geoblosphere Science Centre Physical Geography and Ecosystems Analysis, Lund University, Sweden, 2005.

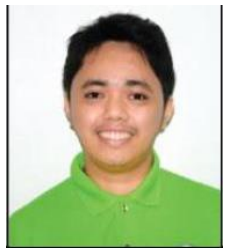

Rovick P. Tarife is an M.S. candidate in electrical engineering at Mindanao State University-Iligan Institute of Technology (MSU-IIT), Iligan city, Philippines. He is currently working as a research assistant at MSU-IIT Phil-LiDAR 2. His research interests are in the field of GIS, renewable energy, and distributed generation (DG).

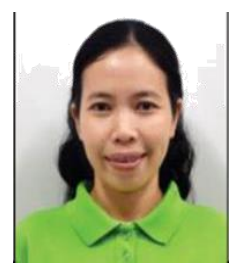

Anacita P. Tahud earned an M.S. degree in electrical engineering in 2015 from Mindanao State University-Iligan Institute of Technology (MSU-IIT), Iligan City, Philippines. She is currently working as a senior science research specialist at MSU-IIT Phil-LiDAR 2. Her research interests are in the field of remote sensing, GIS, renewable energy, hydropower resource assessment, microgrid, and power systems.

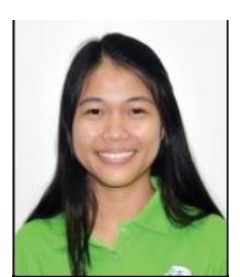

Ellen Jane G. Gulben is an M.S. candidate in electrical engineering at Mindanao State University-Iligan Institute of Technology (MSU-IIT), Iligan City, Philippines. She is currently working as a research assistant at MSU-IIT Phil-LiDAR 2. Her research interests are in the field of remote sensing, hydro \& solar potential, renewable energy, GIS, and PV systems. 


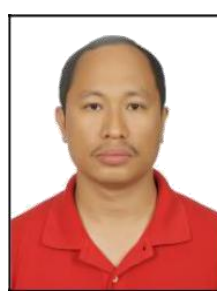

Haroun Al Raschid Christopher P. Macalisang earned an M.S. degree in computer science in 2010 from James Madison University, Virginia, USA. He is currently a professor in the Department of Computer Science, MSU-IIT Iligan City, Philippines. He is also currently working as a project staff at MSU-IIT Phil-LiDAR 2. His research interests are in the field of algorithms, computer vision, image processing, and artificial intelligence.

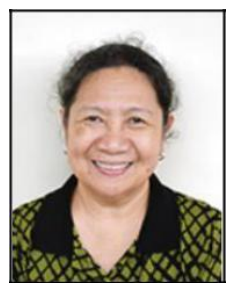

Ma. Teresa T. Ignacio earned an M.S. degree in metallurgical engineering in 1985 from University of the Philippines - Diliman, Quezon City, Philippines. She has been working as a professor in the Department of Metallurgical Engineering, MSU-IIT Iligan City, Philippines. She is also currently working as the project leader of MSU-IIT Phil-LiDAR 2. Her research interests are in the field of LiDAR based resource assessment, metallurgy, and material science. 